\title{
CRÍTICA CULTURAL, CRÍTICA LITERÁRIA: DESAFIOS DO FIM DE SÉCULO
}

\author{
POR \\ Silviano Santiago \\ Universidade Federal Fluminense, Brasil
}

Existe maior dificuldade em interpretar as interpretações do que em interpretar as coisas.

Montaigne

Para abordar com segurança o tema proposto - "Crítica cultural, crítica literaria: desafíos de fin de siglo", será preciso refletir antes sobre um problema de periodização. Em que ano e e em que circunstâncias históricas começa o "fim de século" na América Latina e, em particular, no Brasil? Se nos entregarmos ao trabalho prévio de articular uma série de questões derivadas, a pergunta de caráter geral poderá receber resposta que proponha uma data relativamente precisa. Enunciemos, primeiro, as perguntas derivadas.

Quando é que a cultura brasileira despe as roupas negras e sombrias da resistência à ditadura militar e se veste com as roupas transparentes e festivas da democratização? Quando é que a coesão das esquerdas, alcançada na resistência à repressão e à tortura, cede lugar a diferenças internas significativas? Quando é que a arte brasileira deixa de ser literária e sociológica para ter uma dominante cultural e antropológica? Quando é que se rompem as muralhas da reflexão crítica que separavam, na modernidade, o erudito do popular e do pop? Quando é que a linguagem espontânea e precária da entrevista (jornalística, televisiva, etc.) com artistas e intelectuais substitui as afirmações coletivas e dogmáticas dos políticos profissionais, para se tornar a forma de comunicação com o novo público?

A resposta às perguntas feitas acima levam a circunscrever o momento histórico da transição do século XX para o seu "fim" pelos anos de 1979 a 1981. Se correta a data, compete-nos fazer um trabalho de arqueologia, a fim de que se estabeleça uma primeira bibliografia mínima ${ }^{1}$ e se nomeie a gênese dos problemas que ainda hoje nos tocam. Tanto o leitor quanto o crítico poderão enfrentar com maior rigor os vários desafios que, desde então, se nos apresentam no campo da cultura e da literatura.

Nesses três anos a que estaremos nos referindo, a luta das esquerdas contra a ditadura militar deixa de ser questão hegemônica no cenário cultural e artístico brasileiro, abrindo espaço para novos problemas e reflexões inspirados pela democratização no país (insisto: no país, e não do país). A transição deste século para o seu "fim"se define pelo luto dos que

\footnotetext{
${ }^{1}$ Menos por modéstia e mais por decoro, não cito textos meus que poderiam fazer parte deste debate.
} 
saem, apoiados pelos companheiros de luta e pela lembrança dos fatos políticos recentes, e, ao mesmo tempo, pela audácia da nova geração que entra, arrombando a porta como impotentes e desmemoriados radicais da atualidade. Ao luto dos que saem opõe-se o vazio ${ }^{2} a$ ser povoado pelos atos e palavras dos que estão entrando.

Em artigo publicado em 13 de agosto de $1981,{ }^{3}$ Heloisa Buarque de Hollanda esboçava um primeiro balanço das novas tendências na arte e na cultura brasileiras. A reviravolta que ambas sofriam se devia à passagem recente do furacão soprado pelo cineasta Cacá Diegues, denominado com propriedade na época de "patrulhas ideológicas". O furacão, porque desorientava a esquerda formada nos anos 50 e consolidada na resistência à ditadura militar dos anos 60 e 70, era premonitório da transição. O livro de entrevistas que levou o nome da polêmica - Patrulhas Ideológicas ${ }^{4}$ - se configura hoje mais como o balanço da geração que resistiu e sofreu durante o regime de exceção e menos como a plataforma de uma nova geração que desejava tomar ao pé da letra a "diástole" (apud General Golbery) da militarização do país.

Como narradores castrados pelos mecanismos da repressão, como pequenos heróis com os olhos voltados para o passado doloroso, como advogados de acusação dispostos a colocar no banco dos réus os que de direito ali deveriam ficar para sempre, a maioria dos personagens públicos entrevistados em 1979/1980 quer contar uma história de vida. Resume o cineasta Antônio Calmon: "Eu acho melhor contar a história do que teorizar". Ainda em 1979, sai publicado o emblemático depoimento do ex-guerrilheiro Fernando Gabeira, $O$ que é isso, companheiro?, que narra com minúcia de detalhes o cotidiano redentor e paranóico da guerrilha no Brasil e na América Latina e as sucessivas fugas dos latino-americanos para os vários exílios. Na numerosa produção de relatos de vida, há um tom Christopher Lasch ${ }^{5}$ que impede que o lugar político-ideológico até então ocupado pelo regime militar seja esvaziado e reocupado pelos defensores de uma cultura adversária, ou

\footnotetext{
${ }^{2}$ A noção do "vazio" que toma conta do país durante a ditadura foi estabelecida e consagrada pela esquerda cultural na época. V. "A crise da cultura brasileira", Visão, 5/7/71. Ali se pergunta: "Quais são os fatores que estariam criando no Brasil o chamado "vazio cultural'?" V., ainda, na mesma revista, 11/3/74, o balanço dos dez anos da "revolução".

3 "Bandeiras da imaginação antropológica", O Jornal do Brasil. Trata-se duma resenha do livro do antropólogo Carlos Alberto Messeder Pereira, Retrato de época (um estudo sobre a poesia marginal na década de 70). Rio de Janeiro, Funarte, 1981. O artigo abre por quatro perguntas: "A que vem esse antropólogo, pretendendo mexer com a curiosa tribo dos poetas? Como a pesquisa antropológica vai lidar com o fenômeno literário enquanto objeto empírico? O que significaria, para nós, literatos natos, pensar a literatura relativizada em seu caráter literário? Será que os poetas marginais se tornarão perigosos desviantes?"

${ }^{4}$ São Paulo, Brasiliense, 1980. As entrevistas foram feitas por Heloisa Buarque de Hollanda e Carlos Alberto Messeder Pereira. Segundo Pola Vartuck, responsável pela primeira entrevista com Cacá Diegues, o cineasta tratava de salvaguardar o espaço democrático "da liberdade de criação artística, contra todos os intelectuais que, em nome de partidarismos ideológicos, tenta[va]m impor um tipo de censura". No prefácio ao livro se lê que "o discurso mais tradicional da esquerda começa[va] a voltar à tona e aquelas velhas discussões do papel social da arte, da arte engajada, começa[va]m a pintar de novo, inclusive a nível de cobrança..."

${ }^{5}$ Alusão ao livro The Culture of Narcissism - American Life in an Age of Diminishing Expectations, publicado em 1979.
} 
seja, os esquerdistas renitentes não descobrem que o inimigo não está mais lá fora, do outro lado da cerca de arame farpado, mas entre nós. ${ }^{6}$

O acontecimento "patrulhas ideológicas" fecha não só o período triste da repressão como também o período feliz da coesão na esquerda. Por ser o mais polêmico dos intelectuais brasileiros contemporâneos, Glauber Rocha é o primeiro que põe o dedo no harmônico e fraterno bloco esquerdista para abrir rachaduras. Em 1977, O Jornal do Brasil $^{7}$ propicia, num apartamento carioca, o diálogo entre os quatro gigantes da esquerda brasileira: o antropólogo Darcy Ribeiro, o poeta Ferreira Gullar, o cineasta Glauber Rocha e o crítico de arte Mário Pedrosa. O longo e doloroso debate termina com intervenções abruptas de Glauber. Devido às divergências de opinião, conclui que "o debate não pode ser publicado". Segundo a transcrição, "todo mundo [na sala do apartamento] protesta, grita, reclama da posição de Glauber". Glauber continua a silenciar a fala dos demais. Acrescenta: "Eu, por exemplo, comecei a discordar do Darcy [Ribeiro] a partir de certo momento, mas eu não discordarei publicamente [grifo nosso] do Darcy..." A moderadora do debate não percebe a dimensão da rachadura aberta pela discordância no privado que não podia se tornar pública e reage com o cola-tudo das boas intenções: "o problema é que você [Glauber] está querendo impor um pensamento, quer ganhar uma discussão e não é isso que importa aqui". Glauber termina a conversa amistosa com duas declarações contundentes. A primeira é a de que "não há condições no Brasil de se fazer um debate amplo e aberto" e a segunda, "esse debate já era".

Nos anos seguintes, o debate amplo e aberto não apareceria nos relatos de vida dos excombatentes, não se daria pela linguagem conceptual da história e da sociologia, não seria obra de políticos bem ou mal intencionados. Esse debate amplo e aberto se passaria no campo da arte, considerando-se esta não mais como manifestação exclusiva das belles lettres, mas como fenômeno multicultural que estava servindo para criar novas e plurais identidades sociais. Caiam por terra tanto a imagem falsa de um Brasil-nação integrado, imposta pelos militares através do controle da mídia eletrônica, quanto a coesão fraterna das esquerdas, conquistada nas trincheiras. A arte abandonava o palco privilegiado do livro para se dar no cotidiano da Vida. Esse novo espírito estaria embutido na plataforma política do Partido dos Trabalhadores, PT, idealizado em 1978.

Voltando ao artigo de Heloisa Buarque, percebe-se que ela, ao ler o livro Retrato de época (um estudo sobre a poesia marginal da década de 70), detecta "um certo mal-estar dos intelectuais em relação à sua prática acadêmica" cuja saída estava sendo desenhada pela "proliferação de estudos recentes (reunindo-se aí uma expressiva faixa da reflexão universitária jovem) no registro da perspectiva antropológica". Os setores emergentes da

\footnotetext{
${ }^{6}$ Estas noções foram tomadas de empréstimo a Lionel Trilling, via Stanley Aronowitz: "However, despite relatively little institutional power, the movements of multiculturalism, cultural studies as well as the older gender, race and ethnic studies are perceived by their critics as the true 'enemy within' “. Roll over Beethoven. New England, Wesleyan University Press, 1993, p. 27. V. também p. 22.

${ }^{7}$ Pelas razões a ser expostas, o texto do debate permanecerá inédito durante vinte anos. O citado jornal só publicará o debate nas edições de 23 e 24 de fevereiro de 1997. Segundo José Mário Pereira, em artigo publicado na Tribuna da Imprensa, em 10/3/97, o citado debate será publicado na revista Isto $e ́$, de 25 de janeiro de 1978. Nesta primeira transcrição suprimiram-se todas as palavras de Glauber.
} 
produção intelectual, acrescenta ela, "explicita[va]m certas restrições ao que chamam os 'aspectos ortodoxos' da sociologia clássica e da sociologia marxista".

Segundo Heloisa, a chave da operação metodológica apresentada no livro está no modo como o antropólogo Carlos Alberto dá o mesmo tratamento hermenêutico tanto ao material oriundo das entrevistas concedidas pelos jovens poetas marginais, quanto ao poema de um deles. $O$ texto do poema passa a funcionar como um depoimento informativo e a pesquisa de campo é analisada como texto. O paladar metodológico dos jovens antropólogos não distingue a plebéia entrevista do príncipe poema.

Essa grosseira inversão no tratamento metodológico de textos tão díspares aparentemente inocente porque conseqüência da falta de boas maneiras dum jovem antropólogo - desestabilizaria de maneira definitiva a concepção de Literatura, tal como era configurada pelos teóricos dominantes no cenário das Faculdades de Letras nacionais e estrangeiras. ${ }^{8}$ Conclui Heloisa: "Carlos Alberto parece colocar em suspenso a literatura como discurso específico".

Esvaziar o discurso poético da sua especificidade, liberá-lo do seu componente elevado e atemporal, desprezando os jogos clássicos da ambigüidade que o diferenciava dos outros discursos, enfim, equipará-lo qualitativamente ao diálogo provocativo sobre o cotidiano, com o fim duma entrevista passageira, tudo isso corresponde ao gesto metodológico de apreender o poema no que ele apresenta de mais efêmero. Ou seja, na sua transitividade, na sua comunicabilidade com o próximo que o deseja para torná-lo seu.

A ousadia metodológica representa também uma ousadia geracional. $\mathrm{O}$ poema se desnuda dos seus valores intrínsecos para se tornar um mediador cultural, ${ }^{9}$ encorajando o leitor a negociar, durante o processo de interiorização do texto, a própria identidade com o autor. O poeta marginal é um "perigoso desviante". O poema não é mais um objeto singular; singular é o mapeamento do seu percurso entre os imprevisíveis leitores. A lei da Literatura passa a ser o regulamento lingüístico e comportamental que se depreende do percurso empírico e inesperado dos objetos produzidos em seu nome. Dar significado a um poema, ainda que passageiramente, é torná-lo seu, indiciador de uma resposta cultural efêmera/ definitiva sobre a identidade do indivíduo que o lê e do grupo que - pelo mão a mão dos textos e do baseado, pelo boca a boca das conversas e pelo corpo a corpo das transas amorosas - passa assim a existir.

\footnotetext{
${ }^{8}$ A partir do final dos anos 60 , as diversas metodologias de leitura do texto poético eram oriundas do formalismo russo cujo conceito básico era o de "literaturnost" (literariedade), aportado no Brasil pelas mãos do seu criador, Roman Jakobson, na época às voltas com o Estruturalismo francês e as seis funções da linguagem. Cf. Victor Erlich, The Russian Formalism. The Hague, Mouton, 1965, p. 172. Roman Jakobson, "Lingüística e Poética", em Lingüística e Comunicação. São Paulo, Cultrix, 1969. ${ }^{9}$ Para o estabelecimento da noção do poema e da entrevista como mediadores culturais, estamos usando o conceito de "mediador externo" no "triângulo mimético" que, segundo René Girard, inaugura os jogos da subjetividade romanesca moderna. A transformação do Eu no Objeto do seu desejo, quando mediatizada pelo livro, confere ao sujeito uma força de identificação e de conflito com o modelo privilegiado. V. Mensonge romantique et vérité romanesque. Paris, Grasset, 1961. Para um apanhado geral das idéias do crítico, leia-se a entrevista concedida por ele a Pierpaolo Antonello e João Cezar de Castro Rocha, "L'ultimo dei porcospini”, em Iride, n. 19, setembro-dezembro 1996.
} 
A política é a cultura rebelde de cada dia cujo perfume privado exala no espaço público. Ela não é mais manifestação coesa e coletiva de afronta ideológico-partidária, como no auge da repressão militar. Na medida em que me constituo no desejo pelo outro, passamos nós a compor, num dado período histórico, uma geração autoreferenciada e um universo autoreferenciável. Conclui Heloisa que um dos dados mais atraentes da nova produção acadêmica é "o interesse em estudar seu próprio universo".

Será que no ano seguinte ao da sua publicação, 1981, Patrulhas ideológicas já podia ser dado como retrógrado? Há duas exceções ao tom grandiloqüente, autocomiserativo e trágico dos depoimentos concedidos pelos entrevistados. As palavras do compositor e intérprete Caetano Veloso é uma das exceções. Provocado sobre o retorno na cena artística do discurso tradicional da esquerda, reage com corpo e sensualismo, retirando o exercício político da classe política e decretando a combinação extemporânea da prática política aliada à prática da vida, em distanciamento dos chamados líderes carismáticos da contrarevolução (General Golbery) e da revolução (Fidel Castro). Diz ele que o cantor e amigo Macalé "estava entusiasmado porque falou com o Golbery, mas eu não acho graça, nem em Fidel Castro, nem em ninguém... eu acho tudo isso meio apagado, não sinto muito tesão".

Suas idéias sobre o papel do artista na sociedade, sobre arte e engajamento, sobre a função política e erótica da obra de arte, sobre a produção e disseminação do conhecimento no espaço urbano escapam ao ramerrão do livro. E é por isso que, se não se sente patrulhado, sente que incomoda um número cada vez maior de pessoas, como na história do elefante. É o que constata: "o que mais incomoda [as pessoas] é a minha vontade de cotidianizar a política ou de politizar o cotidiano". Como elemento mediador entre o cotidiano e a política, o fazer - o próprio fazer artístico. Pelo seu produto é que o artista se exprime politicamente no cotidiano. Acrescenta ele: "me sinto ligado a tudo que acontece mas através do que eu faço". Caetano está definindo, no dizer do Raymond Williams de The Long Revolution, "culture as a whole way of life", apagando a conjunção $E$ que ligava tradicionalmente cultura e sociedade.

A outra e segunda exceção no livro de 1980 são as palavras da cientista social Lélia Gonzales, negra e carioca de adoção. De início, denuncia o processo de embranquecimento por que passa o negro quando submisso ao sistema pedagógico-escolar brasileiro, anunciando a futura batalha do multiculturalismo contra o cânone ocidental: "e passei por aquele processo que eu chamo de lavagem cerebral dado pelo discurso pedagógico-brasileiro, porque na medida em que eu aprofundava meus conhecimentos, eu rejeitava cada vez mais a minha condição de negra". Cutucada com vara curta sobre a liderança de São Paulo no movimento negro de esquerda, com o fim de saber se é o intelectual paulista que irá desempenhar o papel de mediador entre o Rio de Janeiro e a Bahia, Lélia não titubeia na resposta: "O Rio de Janeiro é que é o mediador entre Bahia e São Paulo. Porque, por exemplo, o negro paulista tem uma puta consciência política. Ele já leu Marx, Gramsci, já leu esse pessoal todo. Discutem, fazem, acontecem, etc. e tal. Mas de repente você pergunta: você sabe o que é iorubá? Você sabe o que é Axé? Eu me lembro que estava discutindo com os companheiros de São Paulo e perguntei o que era Ijexá. O que é uma categoria importante para a gente saber mil coisas, não só no Brasil como na América inteira. Os companheiros não sabiam o que era Ijexá. Ah! não sabem? Então vai aprender que não sou eu que vou ensinar não, cara!" 
E Lélia conclui de maneira a (1) questionar a assimilação do negro à política de esquerda hegemônica, herdada dos anos 50 e consolidada nos anos de repressão e (2) salientar o papel primordial, e não mais secundário, que a cultura, no caso a negra, passa a ter nas lutas políticas setorizadas, nacionais e internacionais. "Então o caso de São Paulo me lembra muito os negros americanos: puta consciência política, discurso político ocidental... dialetiza, faz, acontece, etc. Mas falta base cultural. A base cultural está reprimida..." Pelas duas observações contidas na citação, Lélia está abrindo a porta para que se represente o Brasil não apenas do ponto de vista da sua ocidentalização (o debate ideológico pelo viés do economismo da teoria sociológica ortodoxa é dado, por ela, como discurso político ocidental e... paulista) mas, e sobretudo, pelo viés das negociações entre as múltiplas etnias que o compõem.

Desrecalcar a base cultural negra no Brasil não significa voltar ao continente africano. Para Lélia, isso é sonho, sonho de gringo. Significa, antes, detectar na formação dita científica e disciplinar dos intelectuais negros paulistas certa neutralidade étnica que abole a diferença e que, por isso mesmo, permite - apenas no privado, lembremo-nos das palavras de Glauber Rocha - a expressão de crenças religiosas subalternas. Lélia afirma: "Nós aqui, no Brasil, temos uma África conosco, no nosso cotidiano. Nos nossos sambas, na estrutura de um Candomblé, da macumba..." Sua fala política se encaminha para a negociação pelas trocas culturais entre negros, brancos e índios, com vistas a um Brasil que seria representado não mais como unidade, mas miscigenado, multicultural, porque não há como negar "a dinâmica dos contatos culturais, das trocas, etc." Nesse sentido, uma das grandes questões colocadas por Patrulhas Ideológicas - a da democratização do Brasil após um longo período de autoritarismo militar - acaba por ter uma resposta desconcertante para a esquerda, também autoritária mas naquele momento em plena crise de autocrítica: "Veja, por exemplo, a noção de Democracia. Se você chegar num Candomblé, onde você pra falar com a Mãe de Santo tem de botar o joelho no chão e beijar a mão dela e pedir licença, você vai falar em Democracia!? Dança tudo." Os grupos étnicos excluídos do processo civilizatório ocidental passam a exigir alterações significativas no que é dado como representativo da tradição erudita brasileira ou no que é dado como a mais alta conquista da humanidade, a democracia representativa. Exigem autonomia cultural.

As diversas outras vozes que rechaçam as patrulhas ideológicas, antes de traduzirem o inevitável interesse/descaso pelas ortodoxias marxistas em tempos de democratização, anunciavam para o Brasil (e o mundo) um fim de século triste e incerto, de diversificadas culturas e espírito comunitário, povoado de micro acontecimentos e de heróis descartáveis, tempo de obras artísticas em nada ambiciosas, em que as identidades (individuais, políticas, sociais, econômicas, etc.) não seriam mais estabelecidas pelos grandes vínculos ou dependências ideológico-partidários no espaço público da cidade. Vínculos e dependências seriam estreitados por laços de solidariedade que se sedimentariam num conhecimento aprofundado das várias culturas que compuseram e estavam a duras penas recompondo um país chamado Brasil. No momento da transição do século XX para o seu "fïm", a Sociologia ${ }^{10}$ e a velha geração de acadêmicos saíam de campo e tomavam lugar na

\footnotetext{
${ }^{10}$ Nesse período e no contexto desta discussão, o trabalho mais instigante no campo da Sociologia é o de Sérgio Micelli, Intelectuais e Classe Dirigente no Brasil (1920-1945). São Paulo, Difel,
} 
arquibacanda, para entrar em campo a Antropologia sob as ordens dos emergentes mapeadores das transformações culturais porque passava o país.

Diante do trabalho antropológico que tanto elogia, Heloisa Buarque como que quer salvar, pelo uso precavido do parênteses, os valores por que lutara no passado e que, no presente, se configuram passadistas: "já há algum tempo, nossos melhores teóricos marxistas empenham-se numa autocrítica (severa demais do meu ponto-de-vista) de sua prática dos anos 60 e vêm procurando absorver novas questões como, por exemplo, a democracia, no sentido de alargar seu campo de reflexão [grifo nosso]".

As atitudes extemporâneas expressas no citado depoimento de Lélia Gonzales abrem o leque das expectativas universitárias para outros campos e objetos de estudo durante os três anos (1979 a 1981) a que estamos nos referindo. As Faculdades de Letras - formadoras de "literatos natos", segundo a expressão brejeira de Heloisa, e dedicadas tradicionalmente ao estudo da cultura duma minoria, no caso a letrada, que se manifesta e dialoga pelo livro, - são despertadas para a cultura da maioria.

São despertadas pela avassaladora presença da música comercial-popular no cotidiano brasileiro. Por estar informada e formada pelo Estruturalismo francês e pelos teóricos da Escola de Frankfurt, o despertar da minoria letrada não foi pacífico. É surpreendente, por exemplo, que a primeira crítica severa à grande divisão ("the Great Divide", segundo a expressão já clássica de Andreas Huyssen ${ }^{11}$ ) entre o erudito e o popular com o conseqüente rebaixamento deste, tenha partido de um jovem intelectual com formação na Universidade de São Paulo, o professor de Letras e músico José Miguel Wisnik. Mais surpreendente, ainda, é que dele tenha partido a primeira leitura simpática e favorável do cantor Roberto Carlos, ainda que, para tal tarefa, o crítico tenha de se travestir pela fala da sua mulher, caindo literalmente numa "gender trap".

Estamos nos referindo ao artigo "O minuto e o milênio ou Por favor, professor, uma década de cada vez", capítulo do livro Anos 70 - 1. Música popular. ${ }^{2}$ "A má vontade para

dezembro de 1979. Segundo o autor, o livro "não deixa de ser uma resposta positiva às análises de Gramsci sobre a Itália, de Bourdieu sobre a França contemporânea, de Williams sobre os escritores ingleses, de Ringer sobre o mandarinato alemão". O capítulo "Os Intelectuais e o Estado", abordando o período do Estado Novo, pode ser lido como uma espécie de reflexão metafórica sobre o recente processo de "co-optação" (uso propositadamente o conceito de Micelli) dos intelectuais brasileiros pelo regime militar imposto em 1964. Deve-se citar, ainda, o livro de Roberto da Matta, Carnavais, malandros e heróis: para uma sociologia do dilema brasileiro. Rio de Janeiro, Zahar, 1979.

" Cf.: "What I am calling the Great Divide is the kind of discourse which insists on the categorical distinction between high art and mass culture. [...] The belief in the Great Divide, with its aesthetic, moral and political implications is still dominant in the academy today (witness the almost total institutional separation of literary studies, including the new literary theory, from mass culture research [...]”. É bom lembrar que a primeira edição de After the Great Divide - Modernism, Mass Culture, Postmodernism, data de 1986. O texto de José Miguel Wisnik, a ser comentado, está datado de outubro/novembro de 1979.

${ }^{12}$ Rio de Janeiro, Europa, 1979-1980, pp. 7-23. Para uma excelente e ampla apreciação da variada produção crítica brasileira sobre música popular, bem como para um mapeamento da questão hoje, leia-se o recente artigo de David Treece, "Melody, Text and Luiz Tatit's $O$ Cancionista: New Directions in Brazilian Popular Music Studies". Latin American Cultural Studies, vol. 5, n. 2, november 1996. 
com a música popular em Adorno é grande”, começa por afirmar José Miguel. Em seguida constata que ela é conseqüência de dois fatores que acabam por nos diferenciar dos europeus, optando o crítico brasileiro pela desconstrução do pensamento adorniano. ${ }^{13} \mathrm{Em}$ primeiro lugar, diz José Miguel, para Adorno, "o uso musical é a escuta estrutural estrita e consciente de uma peça, a percepção da progressão das formas através da história da arte e através da construção duma determinada obra". Em segundo lugar, observa ainda, "o equilíbrio entre a música erudita e a popular, num país como a Alemanha, faz a balança cair espetacularmente para o lado da tradição erudita, porque a música popular raramente é penetrada pelos setores mais criadores da cultura, vivendo numa espécie de marasmo kitsch e digestivo [...]". ${ }^{14}$

José Miguel contrapõe ao soturno quadro erudito europeu um cintilante cenário brasileiro, marcado por "uma poética carnavalizante, onde entram [...] elementos de lirismo, de crítica e de humor: a tradição do carnaval, a festa, o non-sense, a malandragem, a embriaguez da dança, e a súbita consagração do momento fugidio que brota das histórias do desejo que todas as canções não chegam pra contar". Nesse sentido e entre nós, há que primeiro constatar - levando-se em consideração o pressuposto básico levantado por

\footnotetext{
${ }^{13}$ As idéias veiculadas por José Miguel nesse artigo se inserem na atualidade de longo e forte debate no mundo anglo-saxônico, sem no entanto dele (querer) fazer parte, ou tomar partido. Trata-se do debate sobre o pós-modernismo. Faremos uma rápida recapitulação do debate, valendo-nos dos argumentos levantados por Huyssen, na obra já citada. Segundo ele, o pós-modernismo estaria mais próximo da "vanguarda histórica" do que do "modernismo". Mas antes de dar prosseguimento, é bom configurar o que ele entende por um e outro termo, já que se diferenciam da nossa definição. $\mathrm{O}$ "modernismo" (não no sentido brasileiro, insistimos, mas como manifestação erudita da arte) se constituiu através duma estratégia consciente de exclusão da cultura de massa, espécie de ansiedade de contaminação pelo seu outro. A oposição excludente estaria evidente tanto nos movimentos de arte pela arte da virada do século, quanto no período posterior ao fim da Segunda Guerra Mundial. Segundo ainda Huyssen, o mais efetivo ataque às noções de auto-suficiência da cultura erudita neste século vieram do confronto entre a autonomia estética do primeiro "modernismo" com a política vanguardista e revolucionária de origem russa e germânica, logo depois da Primeira Guerra Mundial e com a modernização rápida e acelerada da vida nas grandes metrópoles. Este confronto seria de total responsabilidade da "vanguarda histórica", para usar o conceito de Peter Burger em The Theory of Avant-Garde. A idéia desenvolvida por Huyssen, com a ajuda de Burger, é a de que a "vanguarda histórica" visava a desenvolver uma relação alternativa entre arte erudita e cultura de massa e, dessa forma, deveria ser distinguida do "modernismo", que de maneira geral insistia na tecla da hostilidade entre o erudito e o popular.

${ }^{14}$ No já citado livro de Huyssen, as limitações (ou a "cegueira") de Adorno na análise da cultura de massa são explicadas por razões históricas. Foi-lhe dado viver numa época em que sua teoria tinha mais sentido. Associando Adorno ao crítico de arte Clement Greenberg, Huyssen afirma que os dois "had good reason at the time to insist on the categorical separation of high art and mass culture. The political impulse behind their work was to save the dignity and autonomy of the art work from the totalitarian pressures of fascist mass spectacles, socialist realism, and an ever more degraded commercial mass culture in the West". Ou: "Adorno's blindness have to be interpreted as simultaneously theoretical and historical ones. Indeed, his theory may appear to us today as a ruin of history, mutilated and damaged by the very conditions of its articulation and genesis: defeat of the German working class, triumph and subsequent exile of modernism from Central Europe, fascism, Stalinism and the Cold War".
} 
Antonio Candido para configurar a "formação"15 da literatura brasileira - que "a música erudita nunca chegou a formar um sistema onde autores, obras e público [grifo nosso] entrassem numa relação de certa correspondência e reciprocidade". Apontando na balança dos trópicos desequilíbrio inverso ao apresentado na balança européia, José Miguel retoma uma descoberta clássica de Mário de Andrade, a que diz que no Brasil o uso da música raramente foi o estético-contemplativo (ou o da música desinteressada). Em seguida afirma que, entre nós, a tradição musical é popular e adveio do "uso ritual, mágico, o uso interessado da festa popular, o canto-de-trabalho, em suma, a música como um instrumento ambiental articulado com outras práticas sociais, a religião, o trabalho e a festa".

Estabelecido o contraste entre os dois universos musicais, questionado o eurocentrismo da teoria adorniana, que rebaixa o popular em causa própria, há que relativizar a universalidade analítica da má vontade. No caso brasileiro, não há porque valorizar a música erudita já que não existe uma tradição sólida; não há porque rebaixar a música popular pelos motivos que José Miguel expõe e reproduzimos: "a tradição da música popular [no Brasil], pela sua inserção na sociedade e pela sua vitalidade, pela riqueza artesanal que está investida na sua teia de recados, pela sua habilidade em captar as transformações da vida urbano-industrial, não se oferece simplesmente como um campo dócil à dominação econômica da indústria cultural que se traduz numa linguagem estandardizada, nem à repressão da censura que se traduz num controle das formas de expressão política e sexual explícitas, e nem às outras pressões que se traduzem nas exigências do bom gosto acadêmico ou nas exigências de um engajamento estreitamente concebido". ${ }^{16}$

Através da intervenção dum professor de Letras é que a crítica cultural brasileira começa a ser despertada para a complexidade espantosa do fenômeno da música popular. O seu modo de produção se dá num meio em que as forças mais contraditórias e chocantes da nossa realidade social se encontram sem se repudiarem mutuamente. Em lugar de separar e isolar vivências e experiências, em lugar de introjetar o rebaixamento cultural que lhe é imposto para se afirmar pelo ressentimento dos excluídos, a música popular passa a ser o espaço "nobre", onde se articulam, são avaliadas e interpretadas as contradições sócioeconômicas e culturais do país, dando-nos portanto o seu mais fiel retrato. No trânsito entre as forças opostas e contraditórias, José Miguel aposta em três oposições que, por não o serem, acabam por integrar os elementos díspares da realidade brasileira no caldeirão social

\footnotetext{
${ }^{15} \mathrm{Cf}$.: "Mas há várias maneiras de encarar e de estudar a literatura. Suponhamos que, para se configurar plenamente como sistema articulado, ela dependa da existência do triângulo 'autor-obra-público', em interação dinâmica, e de uma certa continuidade da tradição. Sendo assim, a brasileira não nasce, é claro, mas se configura no decorrer do século XVIII [...]". Formação da Literatura Brasileira. São Paulo, Martins, s/d.

${ }^{16} \mathrm{Na}$ mesma época em que José Miguel escrevia seu texto, Caetano Veloso dizia em Patrulhas Ideológicas (26-10-79): "O caso do Brasil, com música popular, é especial; é muito forte o mercado de música popular, é muito grande o interesse pelo que se faz... inclusive o status intelectual e político da criação de música popular no Brasil. É aberrante esta importância: todo mundo intui uma força cultural, política, intelectual e filosófica na música popular brasileira. E isso existe porque a música popular é muito forte, vem muito de dentro, expressa e atua muito sobre o país. Talvez não do modo como em geral se pensa, mas acho que não poderia haver tudo isso se não houvesse de fato uma "força estranha' na música popular no Brasil..."
} 
em que se cozinha a música popular-comercial: "embora mantenha um cordão de ligação com a cultura popular não-letrada, desprende-se dela para entrar no mercado e na cidade; b) embora deixe-se penetrar pela poesia culta, não segue a lógica evolutiva da cultura literária, nem filia-se a seus padrões de filtragem; c) embora se reproduza dentro do contexto da indústria cultural, não se reduz às regras da estandardização. Em suma, não funciona dentro dos limites estritos de nenhum dos sistemas culturais existentes no Brasil, embora deixe-se permear por eles".

A música popular no Brasil é "uma espécie de hábito, uma espécie de habitat, algo que completa o lugar de morar, o lugar de trabalhar", e é por isso que, no tocante às década de 60 e 70, há que "pensar o oculto mais óbvio": tanto o estrondoso sucesso comercial de Roberto Carlos, quanto a simpatia despertada pela sua "força estranha" em figuras do porte de Caetano Veloso. O crítico pergunta: "que tipo de força o sustém no ar por tanto tempo? Por que ele?" O crítico se sente incapaz de pensar o paradoxo do oculto mais óbvio. Será que isso é tarefa para mim? deve ter perguntado a si antes de dar continuidade ao artigo. José Miguel cai na armadilha do gênero (gender trap), incapaz de responder à questão que é formulada pelo encadeamento orgânico do seu raciocínio analítico. Eis que pede ajuda à sua mulher [sic] para que responda e escreva sobre Roberto Carlos. A profundidade da escuta de Roberto Carlos só pode ser captada por ouvidos femininos. ${ }^{17}$ Vale a pena transcrever o transcrito, deixando o leitor jogar algum alpiste interpretativo no interior da armadilha para que se evidenciem ainda mais as trapaças que o falocentrismo pode pregar:

Ela disse: voz poderosa, suave, louca, ele [Roberto Carlos] realiza melhor do que ninguém o desejo de um canto espontâneo, arranca matéria viva de si e entra em detalhes, coisas mal acabadas, células emocionais primitivas, momentos quase secretos de todo mundo (como as frases decoradas que a gente prepara para lançar ao outro na hora de partir e que não chega a dizer nem a confessar), uma qualidade romântica, ingênua e vigorosa, que unifica a sem-gracice, o patético, a doçura, o lirismo que há em todos, e fica forte, quase indestrutível, pois soma anseios, ilusões, ideais que também pairam por aí, mais além, estranho à realidade cotidiana de muitos.

Dando continuidade à leitura reabilitada do melhor da música popular-comercial brasileira, o critico diz que poderia complementar o seu trabalho, ratificando a liderança que veio sendo concedida por justo mérito a Caetano Veloso. O intérprete torna-se, ao mesmo tempo, lugar de ver a produção dos contemporâneos e lugar onde ela pode ser vista e analisada. Caetano é irônico por cair na armadilha de gênero que ele próprio estabelece no processo de produção das suas canções; Caetano é romântico pela recusa em cair na armadilha de gênero, já que se transforma em ouvinte e intérprete de Roberto Carlos. Para "falar um pouco mais de Caetano a partir de Roberto Carlos" é preciso assumir a fala rebaixada da mulher.

\footnotetext{
${ }^{17}$ Como lembra Huyssen no capítulo "Cultura de Massa como Mulher: o Outro do Modernismo", esse paradigma de rebaixamento do feminino pelo masculino, associando aquele à cultura de massa e este à erudita, foi estabelecido no século XIX: "woman (Madame Bovary) is positioned as reader of inferior literature - subjective, emotional and passive - while man (Flaubert) emerges as writer of genuine, authentic literature - objective, ironic, and in control of its aesthetic means".
} 
Três canções escreveu Caetano para Roberto Carlos: "Como 2 e 2", "Muito romântico" e "Força estranha". Canções, segundo José Miguel, que refletem sobre o ato de cantar e em que, como no caso de Flaubert e Madame Bovary mencionado por Huyssen, todos os recursos de despersonalização e de identificação, de alteridade, são utilizados pelo compositor/intérprete: "minha voz me difere e me identifica; noutras palavras, sou ninguém que sou eu que é um outro". Caetano injetou "reflexão critica" ao romantismo rebaixado/enaltecido de Roberto Carlos. Pela ironia (como escapar dela nesse jogo de espelhos?), ele acentuou "a tensão entre o sentimento romântico e a mediação da mercadoria".

Esse interesse pela música popular-comercial, produzida nos anos 60 e subseqüentes, se complementa com Acertei no Milhar (Samba e Malandragem no Tempo de Getúlio), de Cláudia Matos, originalmente tese de mestrado defendida na PUC-RJ em junho de 1981 e publicada no ano seguinte sob a forma de livro. ${ }^{18}$ Cláudia se interessa pelas letras de samba que, por muito tempo, "constituíram o principal, senão o único documento verbal que as classes populares $^{19}$ do Rio de Janeiro produziram autônoma e espontaneamente". Dentro desse universo textual, Cláudia privilegia o samba de malandro: "o malandro do samba tem uma voz cultural muito mais vigorosa do que o dito malandro em carne e osso".

O principal personagem do samba de malandro é um "ser de fronteira", capaz de transitar entre o morro e a cidade e entre as classes sociais, sendo portanto elemento de mediação social e, por isso mesmo, capaz de armar confrontos e sofrer a violência da repressão. Anota Cláudia: "O malandro não fala apenas para os seus, ao contrário, ele quer se fazer ouvir do outro lado da fronteira, quer abrir caminho para o bloco passar. A vocação para a mobilidade pressupõe o atrito e a troca". Essa ambigüidade do malandro, capaz de sair da cultura negra e de forçar a barra para entrar na cultura branca, interessado em seduzir o seu outro, até obrigá-lo a sair da própria cultura e entrar na sua, torna a cultura negra própria da cidade (o Rio de Janeiro), própria do país (o Brasil). ${ }^{20}$

Entre o atrito e a troca, o malandro é capaz de manipular a linguagem, emprestandolhe efeitos surpreendentes de polissemia onde os significados opostos de um mesmo vocábulo se encontram numa risada estrondosa. O sambista Moreira da Silva costuma narrar esta história de malandro. Se a polícia der em cima, diz o malandro, ou morro ou mato. $\mathrm{O}$ interlocutor se assusta pela postura inédita e radical. $\mathrm{O}$ malandro então retoma as suas próprias palavras: "Se não tiver morro, meto logo a cara no mato".

\footnotetext{
${ }^{18}$ Rio de Janeiro, Paz e Terra, 1982. No livro é estudada, em particular, a produção dos sambistas negros Geraldo (Teodoro) Pereira (1918-1955) e Wilson Batista (1915-1968). A autora não pretende "fazer um estudo propriamente autoral da obra" deles, mas considerá-la "uma amostragem de certos aspectos do imaginário das classes populares cariocas em sua época".

${ }^{19}$ Em nota de pé de página, a autora justifica a escolha do termo "classes populares" na falta de outro mais apropriado: os que existem, como proletariado, parece-lhe "um conceito demasiadamente adstrito à perspectiva econômica, e tende a deixar de lado os setores clandestinos e marginalizados", ou como classes baixas, que "poderia conduzir a lamentáveis equívocos".

${ }^{20}$ A esse respeito, ler o livro de Hermano Viana, O Mistério do Samba. Rio de Janeiro, Zahar/Editora da UFRJ, 1996. Cf.: "Penso especificamente na transformação do samba em ritmo nacional brasileiro, em elemento central para a definição da identidade nacional, da 'brasilidade' (p. 28)". Ou: "Este livro pode ser visto como um estudo das relaç̃̃es entre cultura popular (incluindo a definição do que é popular no Brasil) e construção da identidade nacional" (p. 33). Consultar, ainda, pp. 151-2.
} 
Analisado pelo viés do discurso lírico-amoroso, percebe-se no texto do samba "a influência de um discurso literário, branco, burguês". Nele, a imitação poderia ser sinal de subserviência ao produto original, hegemônico na cidade das letras. Analisada melhor a contaminação de mão única, vê-se que a confluência do mundo popular com o mundo erudito visa antes a apropriação pelo sambista, através do manejo da língua literária, de situações e emoções por assim dizer universais. Conclui Cláudia que "a universalidade do tema amoroso, favorecendo a contaminação do discurso proletário por valores semelhantes aos de um discurso burguês previamente escrito, previamente inscrito na cultura, tendia à obliteração das fronteiras de classe, e não à tomada de consciência de tais fronteiras". Como diz em contexto ligeiramente diferente, mas pertinente: "O malandro manipula o código do outro para poder penetrar à vontade em seu território e contrabandear para lá sua mercadoria e sua voz, o samba". ${ }^{21}$

A ambigüidade do malandro transparece, ainda e sobretudo, no modo como transita pelo morro/cidade. O malandro distingue-se do proletário por andar sempre bem vestido, o que o aproxima dos padrões burgueses. Mas destes se diferencia por ser uma caricatura do burguês. Anota Cláudia: "seu modo de se apresentar inclui aspectos de exagero e deformação tão evidentes que o próprio trajar elegante é um dos elementos pelos quais a polícia o identifica como malandro, e que portanto tornam a jogá-lo no universo das classes oprimidas". Anda na moda, mas transmite impressão de fantasia ou disfarce.

$\mathrm{Na}$ análise de Cláudia, a questão samba serve para recolocar, através da desconstrução da cultura brasileira pela incorporação da produção textual não-letrada das classes populares, uma questão que fascina a Teoria Literária dominante na época, emprestando-lhe um sabor único. Trata-se da questão da autoria e da parceria. ${ }^{22}$ Essa questão foi levantada pelos estudiosos eruditos interessados no bom entendimento da paródia e do pastiche literários. $\mathrm{Na}$ leitura de Cláudia da produção das classes populares cariocas, esses estudiosos vão encontrar um fascinante manual de explicação e de sobrevivência em tempos de democratização.

$\mathrm{Na}$ produção da música negra e do samba, a autoria transcende os limites da individualidade, para ser uma obra coletiva, como está bem exemplificado no caso de "Pelo telefone". A autoria deste samba é disputada por muitos, tendo levado Sinhô a cunhar um aforismo de grande repercussão hermenêutica: "Samba é como passarinho. É de quem pegar". A autoria pode ser explicada também pela conhecida letra que identifica o samba à voz do morro. Todos e cada um no morro são parceiros potenciais. A parceria é distribuída pela comunidade inteira. Mas se o caso "Pelo telefone" é paradigmático nessa discussão é porque a questão da autoria, tal qual os eruditos a entendem, só surge no mundo da cultura

\footnotetext{
${ }^{21}$ Cf. ainda: "A insistência da síncopa que se acentuava no samba do Estácio revelava a incursão do ritmo negro no sistema musical branco. Paralelamente, era toda uma cultura negra que entrava pela avenida dos brancos, pelo consumo dos brancos. Ismael Silva foi bem claro: aquele samba novo era feito para o bloco poder andar. E quando o bloco andou, foi para levar sua bandeira negra, seu ritmo e sua voz própria".

${ }^{22}$ Ver, por exemplo, o célebre artigo de Michel Foucault “O que é um autor?", ou ainda a aula inaugural que pronunciou no Collège de France, L'Ordre du Discours. Ver, também, a teoria de Mikhail Bakhtine, aliás amplamente utilizada pela autora.
} 
negra depois da industrialização no Brasil de duas descobertas tecnológicas. A indústria fonográfica, implantada em 1917, primeiro produz e reproduz exatamente o samba acima mencionado. A indústria radiofônica, implantada em 1923, só em 1932 é que começa, por decreto-lei, a disseminar e colocar o samba em circulação nacional. A profissionalização do compositor negro leva-o de novo à condição de mediador: ao mesmo tempo em que perde a identidade comunitária (morro), divulga-a no mundo dos brancos; ao mesmo tempo em que subverte o mundo dos brancos, ganha a condição de indivíduo dentro do mercado de trabalho (cidade). ${ }^{23}$

Talvez seja correto afirmar que a memória histórica no Brasil é uma planta tropical, pouco resistente e muito sensível às mudanças no panorama sócio-econômico e político internacional. Uma planta menos resistente e mais sensível do que, por exemplo, as nascidas na Argentina, terra natal de Funes, o memorioso. ${ }^{24}$ A passagem do luto para a democratização, alicerçada pela desmemória dos radicais da atualidade, foi dada por passadas largas que uns, e muitos julgam até hoje, precipitadas e prematuras. Para eles, a anistia no Brasil, concedida a todos e qualquer um por decreto-lei, não deixou que o país acertasse contas com o seu passado recente e negro. Desde então, sem planos para o futuro, estamos mancando da perna esquerda, porque o passado ainda não foi devidamente exorcisado. Nesse sentido e dentro do pessimismo inerente à velha geração marxista, a aposta na democratização, feita pelos artistas e universitários entre os anos de 1979 e 1981, abriu o sinal verde para o surgimento nas esquerdas de uma "cultura adversária". Essa aposta e as negociações e traduções por ela propostas são consideradas por eles como (1) uma manifestação a mais do mito da cordialidade brasileira, retomado agora pelo viés da miscinegação, considerada como possibilidade virtual de uma outra nacionalidade em tempos de globalização, (2) uma aceitação passiva dos novos padrões impostos pela sociedade de consumo que vieram embutidos na opção pelo liberalismo democratizante, (3) um endosso em nada formal, aliás, definitivo, da sociedade do espetáculo, em que as regras de excelência do produto são ditadas pelo mercado.

É inegável que os resultados obtidos pelas passadas largas, precipitadas e prematuras, dadas principalmente pelos jovens artistas e universitários, redundaram em questionamentos fundamentais da estrutura social, política e econômica brasileira. Ao encorajar o exguerrilheiro a se transformar de um dia para o outro num cidadão, os desmemoriados ajudavam a desmontar no cotidiano das ruas o regime de exceção, chegando a ser indispensáveis na articulação das pressões populares pelas "diretas já". Ao redimensionarem o passado recente, também redirecionaram o gesto punitivo para a formação cultural do Brasil, estabelecendo estratégias de busca e afirmação de identidade para a maioria da população, que vinha sendo marginalizada desde a Colônia. Ao questionarem o intelectual pelo viés da sua formação pelas esquerdas dos anos 50 , induziram-no à autocrítica e

2.3 Para uma leitura histórico-sociológica do ambiente carioca onde nasceu o samba, consulte-se Roberto Moura, Tia Ciata e a pequena África no Rio de Janeiro. Rio de Janeiro, Funarte, 1983.

${ }^{24} \mathrm{Já}$ a falta de memória dos narradores brasileiros pode ser representada, emblematicamente, pelo Dom Casmurro de Machado de Assis: "Não, não, a minha memória não é boa... Como eu invejo os que não esqueceram a cor das primeiras calças que vestiram! Eu não atino com a das que enfiei ontem. Juro que não eram amarelas porque execro essa cor; mas isso mesmo pode ser olvido e confusão". 
tornaram possível a transição da postura carismática e heróica dos salvadores da pátria para o trabalho silencioso e dedicado de mediador junto às classes populares. Ao acatarem a televisão e a música popular, com suas regras discutíveis e eficientes de popularização dos ideais democráticos, conseguiram motivar os desmotivados estudantes, também desmemoriados, a irem para as ruas e lutar a favor do impeachment do presidente Collor.

\section{Bibliografia}

Anos 70. Rio de Janeiro, Europa Emp. Gráf. e Edit. Litda., 1979-1980. 7 v. [Vol. 1 - Música popular].

Antonello, Pierpaolo e João Cezar de Castro Rocha. "L'ultimo dei porcospini". Iride 19 (setembro-dezembro 1996).

“A pós-graduação no momento das mudanças". Folha de São Paulo (22 de julho de 1979). Aronowitz, Stanley. Roll Over Beethoven. Hanover: Wesleyan University Press, 1993. Arte em revista 5/7 (1983).

Bar, Décio e Regina Echeverria. "Eu quero é mel” [Entrevista: Gilberto Gil]. Veja (10 de janeiro de 1979).

Candido, Antonio. Formação da literatura brasileira. São Paulo: Martins Editora, s/d. Carvalho, Elizabeth. "Um olhar sobre o Brasil dos anos 70". "Encontro com a alma brasileira". O Jornal do Brasil (23 e 24 de fevereiro de 1997, respectivamente). "O que restou do Brasil?" Isto é (25 de janeiro de 1978).

Carvalho, Luis Fernando Medeiros de. Ismael Silva: samba e resistência. Rio de Janeiro: José Olympio, 1980.

Corrêa, Marcos Sá e Zuenir Ventura. "Escrevo sem rancores" [Entrevista: Alfredo Sirkis]. Veja (24 de junho de 1981).

Diegues, Cacá. "O prazer de pensar". Veja (16 de maio de 1979).

Erlich, Victor. Russian Formalism. The Hague: Mouton, 1965.

Gabeira, Fernando. O que é isso, companheiro? Rio de Janeiro: Codecri, 1979.

Girard, René. Mensonge romantique et vérité romanesque. Paris: Grasset, 1961.

Hollanda, Heloisa Buarque de. "Bandeiras da imaginação antropológica". O Journal do Brasil (13 de agosto de 1981).

"Cedez a vez, ceder a voz". O Jornal do Brasil (12 de dezembro de 1981).

e Carlos Alberto Messeder Pereira. Patrulhas ideológicas. São Paulo: Brasiliense, 1980.

Jabor, Arnaldo. "Chega de lamentações (Jabor lança o seu manifesto para a abertura)". Isto $e ́$ (7 de outubro de 1981).

Jakobson, Roman. Lingüistica e comunicação. São Paulo: Cultrix. 1969.

Huyssen, Andreas. After the Great Divide. Bloomington/Indianapolis: Indiana University Press, 1986.

Lasch, Christopher. The Culture of Narscissism. New York: Warner Books [1979].

Matos, Cláudia. Acertei no milhar. Rio de Janeiro: Paz \& Terra, 1982.

Matta, Roberto da. Carnavais, malandros e heróis. Rio de Janeiro: Zahar Editores, 1979.

Miceli, Sérgio. Intelectuis e classe dirigente no Brasil (1920-1945). São Paulo: Difel, 1979. 
Moura, Roberto. Tia Ciata e a pequena África do Rio de Janeiro. Rio de Janeiro: FUNARTE, 1983.

Pellegrino, Hélio. "Terra em transe". O Jornal do Brasil (30 de agosto de 1981) [artigo escrito em 1967 e até então inédito].

Pereira, Carlos Alberto Messeder. Retrato de época. Rio de Janeiro: FUNARTE, 1981.

Rocha, Glauber. "Não sou cobra mandada". Jornal de Brasília (21 de janeiro de 1979).

Rossi, Clóvis e Helena Salem. "Sim, ela existe". (Um inventário do que pensa e faz, hoje, a esquerda brasileira). Isto é (11 de outubro de 1978).

Santiago, Silviano. Vale quanto pesa. Rio de Janeiro: Paz \& Terra, 1982.

Schild, Susana. "Pra frente Brasil". O Jornal do Brasil (23 de junho de 1982). "Chico Buarque em tempo de mudança (Antes era fácil, agora há tons entre o branco e o preto". O Jornal do Brasil (12 de outubro de 1980).

Schwartzmann, Simon. "A miséria da ideologia e os intelectuais - Os brasileiros e o maniqueísmo que nasceu do autoritarismo". Isto é (31 de outubro de 1979).

Schwarz, Roberto. "Cultura e política, 1964-1969". O pai de família e outros ensaios. Rio de Janeiro: Paz \& Terra, 1978.

Sussekind, Flora. Literatura e vida literária. Rio de Janeiro: Jorge Zahar Editor, 1985.

Treece, David. "Melody, Text and Luiz Tatit's O Cancioneiro". Latin American Cultural Studies 5/2 (November 1996).

Veloso, Caetano. Alegria, alegria. Rio de Janeiro: Pedra Q Ronca, s/d.

Ventura, Zuenir. "O intelectual e o poder" [Entrevista: Eduardo Portella]. Veja (21 de fevereiro de 1979).

Vianna, Hermano. O mistério do samba. Rio de Janeiro: Jorge Zahar/Editora UFRJ, 1995.

Visão (5 de julho de 1975 e 11 de março de 1974). 
